SOCIOCULTURAL ATTITUDES AS A MODERATOR OF THE RELATIONS BETWEEN NEGATIVE EATING AND WEIGHT MESSAGES FROM FAMILY MEMBERS AND LATINAS' BODY IMAGE SHAME

A Thesis
presented to
the Faculty of the Graduate School
at the University of Missouri-Columbia
In Partial Fulfillment
of the Requirements for the Degree
Master of Science
by
AVELINA RIVERO
Dr. Sarah E. Killoren, Thesis Supervisor
MAY 2021


The undersigned, appointed by the dead of the Graduate School, have examined the thesis entitled

SOCIOCULTURAL ATTITUDES AS A MODERATOR OF THE RELATIONS BETWEEN NEGATIVE EATING AND WEIGHT MESSAGES FROM FAMILY MEMBERS AND

LATINAS' BODY IMAGE SHAME

presented by Avelina Rivero,

a candidate for the degree of Master of Science,

and hereby certify that, in their opinion, it is worthy of acceptance.

Associate Professor Sarah E. Killoren

Associate Professor Nicole Campione-Barr

Associate Professor Duane Rudy 


\section{DEDICATION}

To my apá y amá, Jorge Rivero y Gloria Herrera, gracias por su amor y apoyo les dedico mi trabajo. Apá y amá thank you for everything. For believing in me and for constantly telling me, "Mija, we are so proud of you..."

To my sisters, thank you for all of your unconditional love and support. Maudi, Gali, and Bridi, you all make me better and help me stay focused. 


\section{ACKNOWLEDGMENTS}

There are several strong women (and Drs. Rudy and Hunt) that I want to acknowledge who have helped me tremendously throughout this process. First, I would love to thank Dr. Sarah E. Killoren. Thank you, thank you, thank you...for your constant push and reminder that I am strong and resilient. Thank you for advocating for me and being my voice. You have helped me so much in so many ways that I do not even know where to begin. You have helped me grow as a young scholar and most importantly helped me find myself through my research. You are truly an amazing advisor, and I am so lucky to have you in my life. Thank you for all of your patience. You are so appreciated, and I am forever grateful to have such a loving and supportive advisor. Seriously, you are the best! I cannot wait to see you in person and hug you again someday.

Second, thank you Drs. Nicole Campione-Barr and Duane Rudy for serving on my committee. I know the time and effort it takes to be a committee member and I extremely grateful that you both agreed to serve. Your questions and advice have helped strengthen my project and helped me grow as a scholar.

Third, to the beautiful women I look up to and hope to become someday: Drs. Lorena Aceves and Gabrielle Kline. Your constant love and guidance have helped me stay focused and grounded. I hope to become a strong scholar like you someday.

Fourth, I would love to acknowledge Dr. Melissa Delgado for seeing something in me, believing in me, and pushing me to pursue graduate school. If it was not for your project, The Voices Project, and your support, I would have never pursued graduate school and studied research that fascinates me. You gave me purpose.

Fifth, Dr. Hunt, I will never forget when you said to me with tears in your eyes, "Avelina, you are going to kick butt in graduate school”. Dr. Hunt, I am kicking butt in graduate school. 


\section{TABLE OF CONTENTS}

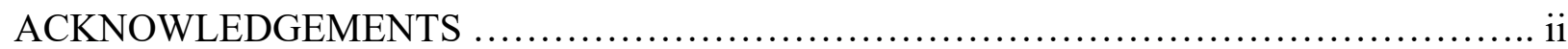

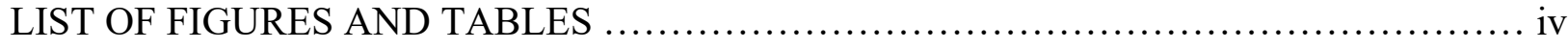

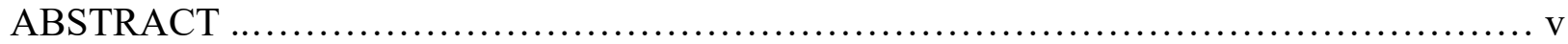

Chapter

1. INTRODUCTION AND LITERATURE REVIEW $\ldots \ldots \ldots \ldots \ldots \ldots \ldots \ldots \ldots \ldots \ldots \ldots . . \ldots \ldots$

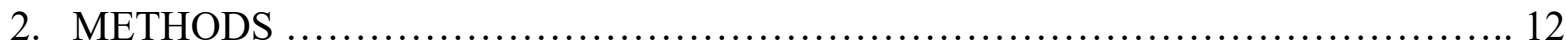

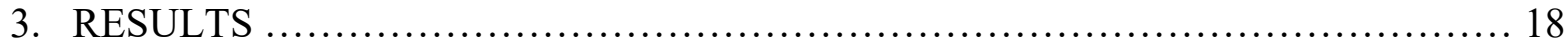

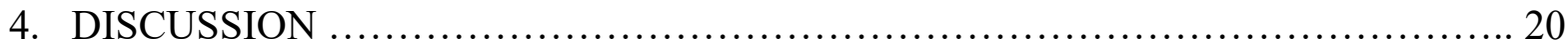

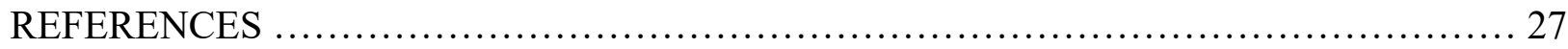

APPENDIX A: FIGURES, APPENDICES, AND TABLES $\ldots \ldots \ldots \ldots \ldots \ldots \ldots \ldots \ldots \ldots \ldots \ldots . \ldots \ldots$ 


\section{LIST OF FIGURES, APPENDICES, AND TABLES}

Figure

1. Conceptual Model

Appendices

1. Appendix A: The Parental Eating and Weight Messages Survey................... 38

2. Appendix B: Sociocultural Attitudes Toward Appearance........................... 39

3. Appendix C: The Body Image Shame Scale............................... 40

Table

1. Correlations and Descriptives............................................. 41

2. Means and Standard Deviations Separately for Older and Younger Sisters

3. Hierarchical Linear Regressions for Internalized Body Image Shame........................ 43

4. Hierarchical Linear Regressions for Externalized Body Image Shame........................ 44

5. Hierarchical Linear Regressions for Internalized Body Image Shame and Externalized Body Image Shame with Step 3 Removed............................................................... 45 


\title{
SOCIOCULTURAL ATTITUDES AS A MODERATOR OF THE RELATIONS BETWEEN NEGATIVE EATING AND WEIGHT MESSAGES FROM FAMILY MEMBERS AND LATINAS' BODY IMAGE SHAME
}

Avelina Rivero

Dr. Sarah E. Killoren, Thesis Supervisor

\begin{abstract}
Research shows that family members are important for young women's body image. Using the sociocultural model, I explored associations between negative eating and weight messages from fathers, mothers, and sisters and Latinas' internalized and externalized body image shame and the moderating role of Latinas' sociocultural attitudes (i.e., internalization of US Western beauty standards) on those associations. I conducted hierarchical linear regression analyses and found positive associations between negative eating and weight messages from fathers and mothers and Latinas' internalized body image shame. Additionally, I found positive associations between negative eating and weight messages from fathers, mothers, and sisters and Latinas' externalized body image shame. Lastly, Latinas’ sociocultural attitudes was positively associated with both internalized and externalized body image shame, but was not a significant moderator. My findings reveal that family members' negative comments are harmful for Latinas' body image. Further, my findings have important clinical implications for practitioners working with Latinx families.
\end{abstract}




\section{CHAPTER 1: INTRODUCTION AND LITERATURE REVIEW}

For many years, body image concerns have been conceptualized as a White woman's issue given that other cultures (i.e., Latinx populations) have primarily been more accepting of thicker body types (Schooler \& Lowry, 2011; Ceballos \& Czyzewska, 2010; Olvera et al., 2016). However, a growing body of literature has demonstrated that Latinas also struggle with and experience body image issues at a similar rate to White women (Breitkopf et al., 2007; Altabe, 1998; Gordon et al., 2010; Schooler \& Lowry, 2011). More recently, researchers have begun to focus on body image shame and the role body image shame may have on mental health concerns for women of different ages, but researchers have neglected to focus on women of color. Body image shame is defined as a sense of disappointment with one's physical appearance when one does not fit societal/cultural standards of beauty, and is operationalized with two levels: internalized and externalized (Duarte et al., 2015). Internalized body image shame occurs when one is participating in degrading self-evaluations (e.g., "I choose clothes that hide parts of my body that I consider ugly or disproportional"). Externalized body image shame occurs when one is preoccupied with the thought that they are being judged for their appearance by others, and thus, avoid social outings (e.g., "I feel uncomfortable in social situations because I feel that people may criticize me because of my body shape"). Externalized body image shame places emphasis on the influence the external world (i.e., society, peers, friends, family) may have on young women's social engagement (e.g., social anxiety) as a result of their appearance (i.e., perception of others) and internalized body image shame is inwardly focused and places emphasis on young women's self-worth and body image concealment. Researchers have argued that both internalized and externalized body image shame are associated with unique implications and outcomes making it crucial to make the distinction (Goss \& Allan, 2009; Duarte 
et al., 2015; Troop et al., 2008). However, in this study, I will be focusing on the unique predictors associated with Latinas' internalized and externalized body image shame. In general individuals who have high levels of body image shame are more likely to have mental health concerns and struggle with eating disorders (Gee \& Troop, 2003; Ferreira et al., 2013; Goss \& Allan, 2009; Van Diest \& Tylka, 2010).

Researchers have widely identified the importance of sociocultural pressures, including pressure from family members, (in addition to peers/friends, media, societal/cultural norms) on the development of body image shame in White women (Duarte et al., 2017; Monro \& Huon, 2005; Markham et al., 2005; Goss \& Allan, 2009; Oliveira et al., 2020). Researchers have identified associations between family members' messages and young women's negative body image outcomes. For instance, appearance-related teasing from family members was associated different outcomes in middle school-aged girls, thus it is crucial that I examine differences by family members messages (Keery et al., 2005). Extending the body image shame research to include the influence of Latinas' family members is important for several reasons: a) because Latinas' spend a lot of time with their family; b) each family member plays a critical role in shaping the family environment and establishing young women's beliefs about themselves and their bodies; c) cultural differences regarding communication; and most importantly d) Latinas' familism values may put them more at risk for experiencing poor body image outcomes because messages from family members may be more impactful (Rogers et al., 2019; Neumark-Sztainer et al., 2010; Keery et al., 2005; Romo \& Mireles-Rio, 2016; Knight et al., 2010). Cultural differences regarding communication exist in Latinx families where nicknames that focus on appearance (e.g., gorda, flaca) are commonly given to young women by family members (Eisenberg, 1986). However, these nicknames may become burdensome and impact young 
women's self-esteem because they are typically appearance-based and young women become more vulnerable and sensitive to physical appearance remarks as they get older (Romo \& Mireles-Rio, 2016).

The sociocultural model can be utilized to examine how society's beauty standards can be transmitted through family members, and directly impact young women's body image outcomes (Tiggemann, 2012; Twamley \& Davis, 1999). Thus, for the current study, I investigated the associations between negative eating and weight messages from family members during adolescence, that is, retrospective reports of messages from fathers, mothers, and sisters, and young women's current internalized and externalized body image shame, while accounting for other family members' messages. Additionally, I examined the moderating role of Latinas' sociocultural attitudes (i.e., internalization of US Western beauty standards) on past negative eating and weight messages from family members and Latinas' current internalized and externalized body image shame. I am focusing on Latinas because sociocultural pressures and cultural differences may force Latinas to feel overwhelmed and stressed, putting them at higher risk for experiencing poor health outcomes (Schooler \& Lowry, 2011; Harris \& Koehler, 1992). For example, Latinas are more likely than any other ethnic/racial group to be overweight and to struggle with comorbidities due to obesity (Schooler \& Lowry, 2011; Isasi et al., 2016).

Moreover, due to Latinas' collectivistic nature, and the prioritization of the family (Stein et al., 2014), it is important to examine the associations between past negative eating and weight messages from family members and body image shame in Latinas.

\section{Theoretical framework}

The current study was guided by the sociocultural model and I examined the associations between fathers', mothers', and sisters' negative eating and weight messages during adolescence and Latinas' internalized and externalized body image shame during young adulthood. The 
sociocultural model has been widely utilized in the body image literature. The sociocultural model highlights the ways in which sociocultural ideals and pressures influence young women's body image outcomes (Tiggemann, 2012). Previous literature has identified the family as an important sociocultural agent that can directly impact young women's body image outcomes. For instance, families can internalize certain beliefs and directly impact young women's perceptions about their bodies through verbal and nonverbal appearance-related messages and conversations (Rogers et al., 2019; Jones, 2011).

\section{Importance of Studying Body Image Shame}

Body image shame occurs when young women compare their bodies to unrealistic cultural beauty norms that are established by societal pressures (Bessenoff \& Snow, 2006). Body image shame is only an issue when young women perceive themselves as not meeting the expected beauty norm. Several studies have revealed that body image shame is associated with eating psychopathologies and distorted body image perceptions in women and is recognized in two dimensions: internalized and externalized (Duarte, Pinto-Gouveia, \& Rodriguez, 2015; Duarte, Pinto-Gouveia, Ferreira, \& Batisa, 2015; Bessenoff \& Snow, 2006). Internalized body image shame is conceptualized as harmful self-evaluations in an effort to determine one's personal worth/social standing and level of attractiveness and is inwardly focused (Duarte et al., 2015; Gilbert, 1998). Internalized body image shame has been associated with self-esteem issues due to self-directed hate and feelings of lack of control (i.e., hopelessness) in young women (Gilbert, 2002; Ferreira et al., 2019; Daye et al., 2014). In addition, researchers have found internalized body image shame to be associated with bulimic tendencies (Troop et al., 2008) this may be because young women are undergoing such behaviors to lose weight to compete socially (Fredrickson et al., 1998). Internal body image shame deals with internal dissatisfaction while 
external body image shame focuses on the influence the external world has on shaping young women's image and behaviors.

Externalized body image shame is conceptualized as believing that other people are judging your body and view you as unattractive because of the way you look (Duarte, PintoGouveia, Ferreira, \& Batisa, 2015; Gilbert, 1998). Young women who struggle with externalizing body image shame assume that they are always being judged or fear that they are being judged for their appearance and, therefore, avoid any social situations. Gilbert (2002) found that external body image shame is associated with frequent feelings of social anxiety and sadness due to severe distress in social situations. Goss and Allan (2009) also found that externalized body image shame was associated with social anxiety in young women. Similar to internal body image shame, researchers have also found external body image shame to be linked with disordered eating behaviors (Oliveria et al., 2020). Both internalizing and externalizing body image shame have strong negative implications for young women's adjustment and researchers should prioritize examining these constructs within the family context with women of color. Moreover, it is important that researchers examine how unique predictors influence young women's body image shame.

\section{Negative Eating and Weight Messages from Family Members and Body Image Outcomes}

Several studies have revealed that receiving negative weight and body-related messages from family members has a detrimental impact on young women's mental and physical wellbeing (Hitti, et al., 2019; Gross \& Nelson, 2000; Diaz de Leon Vasquez \& Unikel Santoncini, 2019; Van Diest \& Tylka, 2010). Negative eating and weight messages from family members may come in many forms such as verbal (i.e., explicit name calling) and nonverbal (i.e., pointing, laughing) weight and body-related teasing. Research also suggests that individual family 
members may differentially influence young women/youth's body image (Keery et al., 2005). Messages from parents may be more salient to young women compared to messages from sisters. In addition, family members can unintentionally encourage other members to give degrading body-related messages through modeling behaviors (i.e., brothers making comments because their fathers made comments about their sisters' bodies) (Keery et al., 2005). Research examining associations between negative eating and weight messages from family members and body image shame is sparse and limited to only examining caregivers from certain populations, and the findings are inconsistent (Markham et al., 2005; Oliveira et al., 2019; Oliveira et al., 2020). In addition, most studies have mainly focused on examining correlations between parenting practices (i.e., parental care, level of overprotection, food restriction) (Goss \& Allan, 2009; Markham et al., 2005) and body image shame. Limited studies exist that have focused on caregiver messages and body image shame (Oliveira et al., 2019; Oliveira et al., 2020). Thus, I extend the current research by focusing on the associations between negative eating and weight messages from not only parents, but also sisters, and Latinas' internalized and externalized body image shame. I focus on sisters as opposed to siblings more generally because researchers have found that sisters tease and criticize young women's physical appearance (Cash, 1995; Toro et al., 2006). Moreover, qualitative studies have found that sisters indirectly influence young women's body image through social comparisons (Spurgas, 2005) and sisters are frequently mentioned as an influential social agent (Paquette \& Raine, 2004).

As aforementioned, messages from family members may vary in importance. For instance, some may argue that messages from mothers are more harmful than messages from fathers because body image concerns have primarily been conceptualized as a women's issue, so a majority of research has focused on mothers. This has led to a scarcity in research examining 
the fathers' role on their daughters' body image. However, the little research that does exist examining both fathers and mothers seems to be mixed. For example, some researchers have found that women receive significantly more weight-related criticism from fathers compared to mothers, and paternal body-related teasing is considered to be more damaging to young women's body image compared to maternal body-related teasing (Keery et al., 2005; Schwartz et al., 1999). However, other researchers have found that mothers provide more appearance-related teasing and criticism compared to fathers (Rieves \& Cash, 1996; Cash, 1995). And sisters have been reported to provide more negative appearance-related comments compared to mothers and fathers (Cash, 1995). To this date, no study has compared the intensity of appearance-related messages from fathers, mothers, and sisters simultaneously. However, I expect that messages from mothers and sisters, relative to fathers, will be more salient to young women because young women model their mother's and sister's behaviors and share similar beliefs and attitudes about body image (Cash, 2011; Jones, 2011; Smolak, 2011).

Literature supports that family members play critical roles in communicating certain beauty standards and expectations (Tiggemann, 2012; Twamley \& Davis, 1999; Cash, 2012; Jones, 2011). Although the family has been identified as having an important influence on young women's body image, very few studies have focused on the associations between family members' messages and internalized body image shame. There is some research that has examined caregivers' messages on young woman's internalized body image shame; however, there has been little discussion about siblings and internalized body image shame. For instance, in a study with college-aged women, researchers found recollections of appearance-related messages from caregivers was positively associated with internalized body image shame (Daye et al., 2014). Yet, it is unknown what associations exist between siblings and internalized body 
image shame. According to social comparison theory (Festinger, 1954), sisters play important roles in developing young women's body image perceptions (Rieves \& Cash, 1996). For instance, researchers have found that young women (especially younger sisters) tend to compare their own bodies to their older sisters' bodies and this process may be damaging if they perceive their body to differ from their sisters' bodies (Tsiantas \& King, 2001; Greer \& Campione-Barr, \& Lindell, 2015). That is, it may be a problem if their sisters' bodies are "thin" while their bodies are "heavier" because it may push young women to participate in unhealthy weight control behaviors in order to look like their sisters (Jones, 2011). Thus, it is important to examine associations between negative eating and weight messages from sisters and young women's internalized body image shame.

Previous literature has also identified relations between messages from caregivers and externalized body image shame. For example, Rogers et al. (2019) found associations between recollections of restrictive/critical caregiver comments about food habits and externalized body image shame in American female undergraduates. That is, participants who reported hearing comments about food intake from their caregivers, reported higher levels of externalized body image shame. Moreover, in a study with Portuguese women whose ages ranged from 18 to 40 , researchers found that participants who reported experiencing restrictive/critical caregiver eating messages also reported higher levels of externalized body image shame (Oliveira \& MartaSimoes, \& Ferreira, 2019). These findings highlight that externalized body image shame is a common cross-cultural phenomenon and is experienced by women of different racial/ethnic groups and different ages. However, researchers have primarily focused on caregivers and have neglected to examine the influence other family members have on young women's external body image shame outcomes. According to social learning theory (Bandura \& Walters, 1977), siblings 
serve as important role models (Smolak, 2011), especially with sharing similar beliefs and attitudes about body image in particular and modeling certain behaviors (Jones, 2011; Coomber \& King, 2008). For example, researchers have found that when one sister reports body dissatisfaction, the other sister is also likely to report body dissatisfaction (Coomber \& King, 2008). Thus, it is important to extend the literature by examining the influence sisters may have on young woman's externalized body image shame.

\section{Sociocultural Attitudes as the Moderator}

Sociocultural attitudes towards appearance refers to one's level of acknowledgment and compliance with US Western societal standards of beauty, such as the thin ideal (Heinberg et al., 1995). Women vary on their endorsement levels of the thin ideal and are at higher risk of experiencing body dissatisfaction when they are more accepting of US Western societal beauty norms. Schooler and Lowry (2011) found that Latinas are at higher risk of experiencing poorer body image outcomes when they are more accepting of Western values and norms. As mentioned previously, a common beauty trend in the United States is the thin ideal. Western cultures have been known to prioritize and glorify thinner body types (Calogero et al., 2007). There is constant pressure for young women to conform to the thin ideal. Researchers have acknowledged that internalizing the thin ideal may play an important role when examining young woman's body image outcomes. That is, women may report struggling with their body image when they internalize the thin ideal. Halliwell and Dittmar (2004) found that women were impacted (i.e., had greater body-focused anxiety) by the magazines with extremely thin models when they internalized the thin ideal. Thus, I expect strong sociocultural attitudes (i.e., high/low endorsement levels of the U.S. beauty norms) to change the strength of the associations between negative eating and weight messages from their fathers, mothers, and sisters and Latinas' internalized and externalized body image shame. 


\section{Current Study}

For this current study, I have four distinct goals based on the sociocultural model (Tiggemann, 2012). First, I examine the associations between negative eating and weight messages from fathers, mothers, and sisters and Latinas' current internalized body image shame. Second, I investigate the associations between negative eating and weight messages from family members and Latinas' externalized body image shame. Third, I explore differences between family members' messages and Latinas' internalized and externalized body image shame. Fourth, I explore how sociocultural attitudes moderates the associations between negative messages from family members and internalized and externalized body image shame.

In the current study, I control for other family members' messages when examining the associations between eating/weight messages and body shame for each family member. By including young women's reports of each family members' messages in the same model, I am able to determine the unique role of one family member over and above the variance accounted for by other family members. Including all family members in the same model is important because each family member plays a unique role on young women's body image development, and messages from each family member may differ in strength (Jones, 2011). Moreover, relationship quality with parents and sisters was also included as a control variable given that relationship quality has been found to influence young women's body image outcomes (Smith et al., 2016; Greer, Campione-Barr, \& Lindell, 2015). Additionally, fathers' and mothers' country of birth were included as control variables because acceptance of body sizes differ across cultures (Schooler \& Lowry, 2011; Olvera et al., 2016). Lastly, birth order was also included as a control variable given that sibling relationship characteristics (i.e., older vs younger sisters) may impact the negative/eating messages. For instance, participants might be more impacted by 
receiving messages from their older sister compared to their younger sister. Keery et al. (2005) found that participants who reported receiving teasing remarks from older sisters reported more negative outcomes compared to participants who reported receiving teasing remarks from a younger sister. I will be including an exploratory hypothesis regarding differences by family members messages because longitudinal research has found that messages from mothers are more salient to young women and sisters are a crucial role model for young women (Smolak, 2011).

\section{Hypotheses}

I. Negative eating and weight messages from family members will be positively and significantly associated with Latinas' internalized body image shame.

II. Negative eating and weight messages from family members will be significantly and positively associated with externalized body image shame.

III. Negative eating and weight messages from mothers and sisters, compared to fathers, will be positively and significantly associated with more internalized and externalized body image shame.

IV. Under conditions of high levels of sociocultural attitudes, the positive association between negative eating and weight messages from family members and high levels of internalized and externalized body image shame will be strongest. Under conditions of low levels of sociocultural attitudes, the positive associations between negative eating and weight messages from family members body image shame will not be as strong.

V. 


\section{CHAPTER 2: METHODS}

\section{Procedures}

The data used for this current study originates from a larger study that focuses on young women's body image outcomes and has already been collected. Amazon Mechanical Turk (Mturk) was used to recruit participants. MTurk has been widely utilized in the social sciences due to its accessibility and affordability (Kees et al., 2017). In order to ensure quality data, we included restrictions, such as time taken to complete and password protection, as well as quality assurance items to check that participants were paying attention when they completed the study. For instance, participants were asked, "For quality assurance, please enter your zip code." Participants were self-enrolled into Mturk, and completed the survey using Qualtrics, an online survey platform. Through Qualtrics, participants first received general information about the survey and were required to complete a consent form. When participants provided consent, they were then required to complete a pre-survey. A pre-survey was utilized as a tool to establish eligibility. The pre-survey consisted of 7 questions: a) Do you identify as Latina/o or Hispanic?; b) How old are you (in years)?; c) Do you identify as Male or Female?; d) Do you have a sister?; e) Do you have a sister who is between 1 and 4 years older than you?; f) Do you have a sister who is between 1 and 4 years younger than you?; and g) Have you ever been diagnosed with an eating disorder? Participants who did not meet the inclusion criteria were unable to complete the online survey. However, participants who did meet the inclusion criteria and completed the survey, were paid $\$ 3.00$.

\section{Participants}

Participants $\left(N=190 ; M_{\text {age }}=23.24, S D=1.95\right)$ were included in the study if they met the following criteria: a) identified as Latina/Hispanic young adults between the ages of 18 to 25 ; b) 
had a sister who is between 1 and 4 years younger or old; and c) had never been diagnosed with an eating disorder. Among the participants, 67.4\% described themselves as Mexican/Mexican American/Chicano, 15.3\% as Puerto Rican/Puerto Rican American, 11.1\% as Cuban/Cuban American, $10.0 \%$ as Dominican/Dominican American, $1.6 \%$ as Central American, and 0.5\% as South American. Participants were also asked to report their current year in college: first (6.8\%), second (10.5\%), third (19.5\%), fourth (41.6\%), fifth (13.2\%), and sixth (8.4\%) year. Moreover, a majority of participants reported that they are smaller than they want to be and just the way they want to be $(80.5 \%)$ while others reported that they are bigger than they want to be $(19.5 \%)$. Further, a majority of participants described their fathers (89.5\%) as Hispanic/Latino and their mothers (83.7\%) as Hispanic/Latina. In addition, a majority of participants reported that their fathers $(69.5 \%)$ and mothers $(73.2 \%)$ were born in the U.S. Most participants' fathers $(60.5 \%)$ and mothers $(51.6 \%)$ had at least a college degree or trade school certification. The participants were also asked to report their sister's age, and the average age gap between sisters was 2.46 years $(S D=0.93$; range 1 to 4$)$.

\section{Measures}

Negative eating and weight messages from family members. Negative eating and weight messages from family members (i.e., mother, father, sister) were assessed utilizing an adapted version of the 26-item scale, parental eating and weight messages survey (PEWM; Gross \& Nelson, 2000). Individuals self-reported the extent to which they have heard statements from parents and sisters while growing up with each item using a 5-point Likert scale that ranges from (always) to (never). Sample items include: "You need to lose weight" and "You look like you have gained weight" Items were averaged and reverse coded with lower scores indicating less frequency of body-related verbal messages from family members and higher scores indicating 
higher frequency. This measure has been utilized with female undergraduate students (Gross \& Nelson, 2000; Hanna \& Bond, 2006). Cronbach's alphas were acceptable for fathers ( $\alpha=.96)$, mothers $(\alpha=.95)$, and sisters $(\alpha=.95)$. Because this measure has not been used in studies with exclusively Latina samples, confirmatory factor analyses were conducted. The model was a good fit to the data regarding messages from fathers, $\chi^{2}(2)=56.61, p<.05$, RMSEA $=.06(90 \% \mathrm{CI}$ $=.03, .08), \mathrm{CFI}=.98, \mathrm{SRMR}=.03$ (standardized factor loadings ranged from .82 to .90 ); mothers, $\chi 2(2)=82.58, p<.01, \mathrm{RMSEA}=.08(90 \% \mathrm{CI}=.06, .12), \mathrm{CFI}=.95, \mathrm{SRMR}=.04$ (standardized factor loadings ranged from .74 to .86); and for sisters, $\chi 2(2)=56.91, p<.05$, RMSEA $=.06(90 \% \mathrm{CI}=.03, .08), \mathrm{CFI}=.98, \mathrm{SRMR}=.03$ (standardized factor loadings ranged from .79 to .86$)$.

Sociocultural attitudes towards appearance. Participants' sociocultural attitudes of US Western standards of beauty were assessed utilizing the internalized subscale of the sociocultural attitudes towards appearance questionnaire (SATAQ; Heinberg, Thompson, \& Stormer, 1995). The subscale required participants to report their level of acceptance of societal standards of beauty and includes eight-items that are assessed using a 5-point Likert scale ranging from 1 (completely disagree) to 5 (completely agree). Sample items include: "women who appear in TV shows and movies project the type of appearance that I see as my goal" and "attractiveness is very important if you want to get ahead in our culture.” Items were averaged with higher scores indicating high levels of agreement with US Western standards of beauty. Adapted versions of this questionnaire have been utilized with a Latina college sample (Cordero, 2011). Cronbach alpha was acceptable $(\alpha=.86)$.

Internalized and externalized body image shame. Participants' internalized and externalized body image shame was assessed utilizing both subscales of the body image shame 
scale, which consists of 15-items (BISS; Duarte, Pinto-Gouveia, Ferreira, \& Batista, 2015). Individuals self-reported the extent to which they agree with each item using a 5-point Likert scale that ranges from 0 (never) to 4 (almost always). Example items include: "I avoid social situations (e.g., going out and parties) because of my physical appearance" and "I avoid wearing tight clothes that reveal my body shape." Items were averaged with higher scores indicating higher internalized and externalized body image shame. This scale has been utilized with a college sample and has provided reliable estimates (Webb et al., 2016). Cronbach's alphas were acceptable for internalized $(\alpha=.95)$ and externalized $(\alpha=.94)$ body image shame. Because this measure has not been used in studies with exclusively Latina samples, confirmatory factor analyses were conducted. The model was a good fit to the data, $\chi^{2}(2)=104.46, p>.01$, RMSEA $=.03(90 \% \mathrm{CI}=.00, .05), \mathrm{CFI}=.99, \mathrm{SRMR}=.03$, and standardized factor loadings ranged from .76 to .89 .

Covariates. Participants' relationship quality with parents and sister, fathers' and mothers' place of birth, and birth order were included as covariates. Relationship quality with parents was assessed with an eight-item adapted version of the children's report of parental behavior (CRPBI; Schwarz et al., 1985). Individuals self-reported the extent to which they agree with each item using a 6-point Likert scale that ranges from 1 (almost never) to 5 (almost always). Example items include: "My (mother/father) makes me feel better after talking over my worries with her/him" and "My (mother/father) sees my good points more than my faults." Items were averaged with higher scores indicating more parental warmth and acceptance. Cronbach's alphas were acceptable for fathers $(\alpha=.88)$ and mothers $(\alpha=.88)$. Relationship quality with siblings was examined with an eight-item scale that assesses sibling intimacy (Blyth \& Foster-Clark, 1987). Individuals self-reported the extent to which they agree with each item 
using a 5-point Likert scale that ranges from 1 (not at all) to 4 (very much). Example items include: "How much do you go to your sibling for advice or support?" and "How much do you want to be like your sibling?" Items were averaged with higher scores indicating positive relationship quality. Cronbach alpha was acceptable for sisters $(\alpha=.79)$. Fathers' and mothers' places of birth were assessed with two items, "Was your father/mother born in the U.S.?" with 0 $=$ No and $1=$ Yes. Lastly, birth order was coded $0=$ younger sister and $1=$ older sister .

\section{Analytic Plan}

Prior to conducting the hierarchical linear regression analyses, measures of central tendency (i.e., mean, median, and mode) and variability (i.e., standard deviation, variance, kurtosis, and skewness) were conducted in SPSS to check for normally distributed variables. Further, bivariate correlations in SPSS were also conducted for all study variables. In addition, I conducted psychometric analyses, including reliability and exploratory and confirmatory factor analyses, for measures that have not been used with Latina young adult populations. Moreover, I conducted a series of t-tests to examine if significant differences in main study variables existed based on birth order.

To test the current hypotheses, two hierarchical linear regression models were conducted: one for internalized body image shame and one for externalized body image shame. The predictor, control, and moderator variables were centered prior to creating interaction terms and entering variables into the regression models (Aiken \& West, 1991). Dichotomous control variables were dummy coded (i.e., coded as 0 and 1). In step one of the linear regression analyses, relationship quality with fathers, mothers, and sisters, parents' place of birth, and birth order were entered. In step 2, negative eating and weight messages from fathers, mothers, and sisters and sociocultural attitudes toward appearance were entered. Lastly, in step 3, the two-way 
interaction variables (e.g., Negative Eating and Weight Messages from Fathers X Sociocultural Attitudes) were entered and examined. Any significant interactions were interpreted by plotting the simple slopes for the moderator at one standard deviation above the mean and one standard deviation below the mean. 


\section{CHAPTER 3: RESULTS}

\section{Descriptive Statistics and Correlations}

Descriptive statistics and bivariate correlations are shown in Table 1. All study variables were normally distributed. Messages from family members were all positively associated with one another. Further, fathers', mothers', and sisters' negative eating and weight messages were positively associated with both internalizing and externalizing body image shame. Latinas' sociocultural attitudes were positively associated with family members' messages. Moreover, Latinas' sociocultural attitudes were positively associated with Latinas' internalized and externalized body image shame.

\section{Series of $t$-Tests and Hierarchical Regression Analyses}

A series of t-tests were conducted to examine differences in main study variables by birth order and are shown in Table 2. Participants who were older sisters reported receiving significantly more messages from fathers $(M=2.76, S D=1.01)$, mothers $(M=2.78, S D=.93)$, and sisters $(M=2.74, S D=.96)$ than did participants who were younger sisters (messages from fathers $M=2.06, S D=.98$; mothers $M=2.16, S D=1.05$; sisters $M=2.05, S D=.95)$. Moreover, participants who were older sisters reported significantly higher levels of internalized $(M=2.10$, $S D=1.11)$ and externalized $(M=2.01, S D=1.11)$ body shame and sociocultural attitudes $(M=$ $3.54, S D=.70)$ than did participants who were younger sisters (internalized $M=1.55, S D=1.20$; externalized $M=1.37, S D=1.18$; sociocultural attitudes $M=3.12, S D=.85$ ). Because there were significant birth order differences in the dependent variables, I will be controlling for birth order.

In all of the models (see Table 3 and Table 4), the 2-way interactions were not significant, thus I did not include the third step in the final regression model or the results (see 
Table 5). In the model assessing internalized body image shame, the first step $(F(6,181)=3.39$, $p<.01)$ and second $(F(10,177)=19.32, p<.01)$ steps were significant. The second step resulted in a significant change to the $R^{2}$ (change in $R^{2} .42, p=.00$; total adjusted $R^{2}=.50$ ). Sociocultural attitudes and negative eating and weight messages from fathers and mothers were positively associated with internalized body image shame. That is, higher levels of sociocultural attitudes and more negative messages from fathers and mothers were associated with more internalized body image shame by Latinas.

In the model assessing externalized body image shame, the first step $(F(6,181)=5.43, p$ $<.01)$ and second $(F(10,177)=20.73, p<.01)$ steps were significant. The second step resulted in a significant change to the $R^{2}$ (change in $R^{2} 37.18, p=.00$; total adjusted $R^{2}=.51$ ).

Sociocultural attitudes and negative eating and weight messages from fathers and mothers were positively associated with externalized body image shame. That is, higher levels of sociocultural attitudes and more negative messages from fathers and mothers were associated with more externalized body image shame. Moreover, I found that negative messages from sisters was inversely associated with externalized body image. 


\section{CHAPTER 4: DISCUSSION}

This study is the first to utilize the sociocultural model to examine the associations between fathers', mothers', and sisters' negative eating and weight messages and Latinas' internalized and externalized body image shame. The results indicated that fathers' and mothers' messages and Latinas' sociocultural attitudes were positively associated with Latinas’ internalized and externalized body image shame. In addition, the results also revealed that sisters' messages were negatively associated with Latinas' externalized body image shame. These findings demonstrate that family members play a crucial role in young women's body image outcomes. Moreover, it is important to highlight that Latinas' sociocultural attitudes (i.e., internalizing U.S.'s beauty standards) were significantly and positively associated with Latinas' internalized and externalized body image shame. These findings bring awareness to the importance of family members and societal beliefs/attitudes about beauty have on young women's body image perception and, in turn, align with the sociocultural model's tenets.

\section{Latinas' Internalized Body Image Shame}

I examined associations between negative eating and weight messages from family members and Latinas' internalized body image shame. Internalized body image shame develops when an individual participates in self-degrading evaluations and engages in behaviors that hides their bodies (e.g., "I pay close attention to the movements and posture of my body to hide parts that I do not like”) (Duarte et al., 2014). Providing some support for my hypotheses, fathers' and mothers' negative eating and weight messages were positively and significantly associated with Latinas' internalized body image shame, but sisters' messages were not. In addition, I did not

find support for my exploratory hypothesis. I expected that mothers' and sisters' messages would be the most salient to young women given that research has identified mothers and sisters as 
important sociocultural agents who influence young women's body image (Smolak, 2011). Although I did not find support for my hypothesis, it is important to note that to date no study has included multiple family members (i.e., mothers, fathers, sisters) in the same model to examine young women's body image shame, thus this finding extends the current literature by emphasizing that fathers play an important and direct role, over and above the roles of mothers and sisters. Specifically, fathers' messages may be salient because they represent a male perspective for these young women (Keery et al., 2005). As a result, young women may strive to reach certain beauty ideals based on fathers' messages in an attempt to be desirable to romantic partners (Wertheim \& Paxton, 2011).

Further, parents' messages may hold a higher precedence over sisters' messages, which may help explain why fathers' and mothers' messages were particularly important for young women's internalized body image shame. Moreover, young women seek validation and constant approval from their parents more so than sisters (Jones, 2011; Cash, 2011). Parents also play an important role in controlling the family environment and focus (Schaefer \& Salafia, 2014). Thus, parental messages may lead young women to conceal their bodies and be judgmental about themselves compared to messages from sisters (Jones, 2011).

Similarly, it is important to acknowledge that mothers' and sisters' messages may have not been as impactful as fathers' because it is common for young women to engage in fat talk with their mother and sister, thus fat talk may not be as harmful as we expect (MacDonald et al., 2015). Fat talk refers to negative body-related talk and occurs when individuals engage in selfdegrading conversations with other people (Shannon \& Mills, 2015). In a study with young women, the researchers found that young women reported engaging in fat talk the most with their mothers (MacDonald et al., 2015). When young women engage in fat talk, it is often 
reciprocated with positive reassuring messages and this in turn may help buffer against poor outcomes (Romo \& Mireles-Rios, 2016; Katrevich, Register, \& Aruguete, 2014).

\section{Latinas’ Externalized Body Image Shame}

I also examined the linkages between negative eating and weight messages from family members and Latinas' externalized body image shame. Externalized body image shame develops when an individual assumes that their body image will be subject to criticism by their peers (or others) and, in turn, participates in defense mechanism behaviors to avoid judgement (Duarte et al., 2014). Towards this aim, I found that fathers' and mothers messages were positively and significantly associated with Latinas' externalized body image shame, supporting my hypothesis. I also found that sisters' messages were negatively associated with young women's externalized body image shame. Similar to Roger and colleagues (2019) findings, I also found that messages from parents were positively and significantly associated with young women's external body image shame. However, it is important to note that sisters were not included in Roger and colleagues (2019) model. My findings revealed that along with parents' messages, sisters' messages were important for young women's external body image shame. Given the focus external body image shame places on the social context, messages from sisters may have been salient because they hang out with their sister's friends and/or because sisters are often viewed on the same level as friends. Thus, young women may perceive that their sister can judge their appearance forcing them to hide parts of their bodies to limit criticism.

However, it is important to note that the finding with sisters' messages resulted in a negative significant association when sisters' messages were included in the same model with parents' messages. When sisters' messages were in a separate model, the association between sisters' messages and Latinas' externalized was positively and significantly associated. In 
addition, it is important to note that sisters' messages were positively correlated with parents' messages and Latinas' externalized body image. Several steps were taken (i.e., several regression analyses removing each control and main study variables separately) to ensure that this was in fact an issue of suppression (i.e., third variable effect). Suppression occurs when a variable influences the predictive validity and thus impacts the relationship (i.e., direction) between the independent and dependent variable (MacKinnon, Krull, \& Lockwood, 2000). I also standardized all of the variables in the model and conducted several regression analyses to check

for suppression. Suppression may have occurred because messages from sisters were highly correlated with messages from fathers and mothers. Thus, the finding regarding messages from sisters should be taken with caution.

\section{Latinas' Sociocultural Attitudes Towards Appearance}

The last and final aim was to examine the moderating role of Latinas' sociocultural attitudes on the associations between negative eating and weight messages from family members and Latinas' internalized and externalized body image shame. Regarding the last aim, I did not find any evidence to support the last hypothesis. The relationship between negative eating and weight messages from family members and Latinas' internalized and externalized body image shame were not moderated by Latinas' sociocultural attitudes. Instead, Latinas' sociocultural attitudes were directly associated with Latinas' internalized and externalized body image shame. These findings have important implications for young women's health because Latinas who internalize U.S. standards of beauty may be more at risk for experiencing high levels of body image shame. In general, sociocultural attitudes are often ingrained in young women to the point where young women begin to misinterpret these ideas as their own and use them to determine their worth, which makes it harder for young women to challenge the expectations (McKinley, 
2011). Thus, it may be beneficial for future scholars to examine the indirect effects of Latinas' sociocultural attitudes on the relationship between messages from family members and Latinas' body image shame. For instance, Latinas may fall victim to internalizing certain beliefs about beauty because of family members' messages and, in turn, may feel pressure to meet these standards and struggle with body image shame.

\section{Limitations and Future Directions}

While the present study contributes to the literature by focusing on the impact several family members have on young women's body image shame, there were several limitations. The data used in this study comes from cross-sectional data and thus I cannot infer temporal precedence. For instance, maybe Latinas with high levels of internalized and externalized body shame interpret family members' messages to be more negative than intended. Additionally, the sample was recruited through MTurk. Although, several researchers have successfully utilized MTurk as a data collection tool, many may argue that MTurk lacks generalizability. Given the impact internalizing U.S. standards of beauty has on Latinas, it may be important for scholars to examine how these findings may differ for Latinas' based on their acculturation to the U.S. and to examine whether or not acculturation status is a protective factor against internalizing certain beliefs and poor body image outcomes. Moreover, future scholars should prioritize examining the role messages from brothers may have on young women's body image shame. Berge and colleagues (2016) have revealed that brothers provide more appearance-related criticism compared to sisters and these messages are extremely salient to young women. Moreover, researchers should examine beauty differences within Latinx populations. Just like any racial/ethnic group, a false assumption exists that Latinx populations are a culturally homogenous group. Much body image literature has grouped Latinos into panethnic samples, 
failing to examine the differences that may exist among these populations (Schooler \& Lowry, 2011). Thus, it is important to examine if beauty differences exist within Latinx subgroups because their lack of homogeneity may lead to different cultural beauty values and, as a result, young women's satisfaction with their appearance may vary.

\section{Study Contributions and Implications}

Despite the limitations of the current study, the results make important contributions to the existing body image literature. First, unlike previous studies, the results of this study indicate and highlight that fathers contribute to young women's body image development. More importantly, fathers may play a more salient role compared to mothers and sisters in the development of young women's body image outcomes. Second, it is crucial to note that Latinas are often neglected in the body image literature, so the current study sought out to focus solely on Latinas. Third, sisters were included in the model to gain a deeper understanding about the full family context.

The current study's results also have important clinical implications. For instance, the results demonstrate that appearance-related messages from family members are harmful to young women, and family members should be taught about the consequences of their negative messages.

This is important because body image shame has been linked to eating disorders and poor adjustment outcomes (Duarte, Pinto-Gouveia, \& Rodriguez, 2015; Duarte, Pinto-Gouveia, Ferreira, \& Batisa, 2015; Bessenoff \& Snow, 2006; Markham et al., 2005). Young women diagnosed with an eating disorder are at a higher risk of mortality due to suicide (Smith, 2018).

\section{Conclusion}

The results of this study indicate that Latinas also struggle with their body image and family members play a critical role in shaping young women's body image outcomes. Messages from family members may pose harmful effects on young women's ability to establish a healthy 
body image. Specifically, the findings of this study suggest that family members messages may be a factor contributing to young women's body image shame. The evidence from this study suggests that parents were important for both internal and external body image shame while sisters were only important for external body image shame. Although sociocultural attitudes did not moderate the associations between family members' messages and Latinas' body image shame, I found that sociocultural attitudes were also important for body shame. Future efforts should be made to develop a program that provides families with strategies to help young women appreciate and accept their bodies. Additionally, future prevention programs must prioritize teaching family members about the negative influence they have on young women's body image. 


\section{REFERENCES}

Aiken, L. S., West, S. G., \& Reno, R. R. (1991). Multiple regression: Testing and interpreting interactions. sage.

Altabe, M. (1998). Ethnicity and body image: Quantitative and qualitative analysis. International journal of eating disorders, 23(2), 153-159. https://doi.org/10.1002/(SICI)1098108X(199803)23:2<153::AID-EAT5>3.0.CO;2-J

Bandura, A., \& Walters, R. H. (1977). Social learning theory (Vol. 1). Englewood Cliffs, NJ: Prentice-hall.

Bessenoff, G. R., \& Snow, D. (2006). Absorbing society’s influence: Body image selfdiscrepancy and internalized shame. Sex Roles, 54(9-10), 727-731. DOI 10.1007/s11199006-9038-7

Berge, J. M., Hanson-Bradley, C., Tate, A., \& Neumark-Sztainer, D. (2016). Do parents or siblings engage in more negative weight-based talk with children and what does it sound like? A mixed-methods study. Body image, 18, 27-33. https://doi.org/10.1016/j.bodyim.2016.04.008

Blyth, D. A., \& Foster-Clark, F. S. (1987). Gender differences in perceived intimacy with different members of adolescents' social networks. Sex Roles, 17(11-12), 689-718. https://doi.org/10.1007/BF00287683

Breitkopf, C. R., Littleton, H., \& Berenson, A. (2007). Body image: A study in a tri-ethnic sample of low-income women. Sex Roles, 56(5-6), 373-380. DOI 10.1007/s11199-0069177-X 
Calogero, R. M., Boroughs, M., \& Thompson, J. K. (2007). The impact of Western beauty ideals on the lives of women: A sociocultural perspective. In The body beautiful (pp. 259-298). Palgrave Macmillan, London. https://doi.org/10.1057/9780230596887_13

Cash, T. F. (1995). Developmental teasing about physical appearance: Retrospective descriptions and relationships with body image. Social Behavior and Personality: an international journal, 23(2), 123-130. https://doi.org/10.2224/sbp.1995.23.2.123

Cash, T. F. (2012). Cognitive-behavioral perspectives on body image. Body image: A handbook of science, practice, and prevention, 39-47.

Ceballos, N., \& Czyzewska, M. (2010). Body image in Hispanic/Latino vs. European American adolescents: implications for treatment and prevention of obesity in underserved populations. Journal of health care for the poor and underserved, 21(3), 823-838. DOI 10.1353/hpu.0.0333

Coomber, K., \& King, R. M. (2008). The role of sisters in body image dissatisfaction and disordered eating. Sex Roles, 59(1-2), 81-93. DOI 10.1007/s11199-008-9413-7

Daye, C. A., Webb, J. B., \& Jafari, N. (2014). Exploring self-compassion as a refuge against recalling the body-related shaming of caregiver eating messages on dimensions of objectified body consciousness in college women. Body Image, 11(4), 547-556. https://doi.org/10.1016/j.bodyim.2014.08.001

Díaz de León Vázquez, C., \& Unikel Santoncini, C. (2019). Parental negative weight/shape comments and their association with disordered eating behaviors: A systematic review. Revista Mexicana de Trastornos Alimentarios, 10(1), 134-147.

Duarte, C., Pinto-Gouveia, J., Ferreira, C., \& Batista, D. (2015). Body image as a source of shame: A new measure for the assessment of the multifaceted nature of body image 
shame. Clinical Psychology \& Psychotherapy, 22(6), 656-666.

https://doi.org/10.1002/cpp.1925

Duarte, C., Pinto-Gouveia, J., \& Rodrigues, T. (2015). Being bullied and feeling ashamed: Implications for eating psychopathology and depression in adolescent girls. Journal of adolescence, 44, 259-268. https://doi.org/10.1016/j.adolescence.2015.08.005

Duarte, C., Matos, M., Stubbs, R. J., Gale, C., Morris, L., Gouveia, J. P., \& Gilbert, P. (2017). The impact of shame, self-criticism and social rank on eating behaviours in overweight and obese women participating in a weight management programme. PloS one, 12(1), e0167571. https://doi.org/10.1371/journal.pone.0167571

Ferreira, C., Dias, B., \& Oliveira, S. (2019). Behind women's body image-focused shame: Exploring the role of fears of compassion and self-criticism. Eating behaviors, 32, 12-17. https://doi.org/10.1016/j.eatbeh.2018.11.002

Festinger, L. (1954). A theory of social comparison processes. Human relations, 7(2), 117-140. https://doi.org/10.1177/001872675400700202

Fredrickson, B. L., Roberts, T. A., Noll, S. M., Quinn, D. M., \& Twenge, J. M. (1998). That swimsuit becomes you: sex differences in self-objectification, restrained eating, and math performance. Journal of personality and social psychology, 75(1), 269. https://doi.org/10.1037/0022-3514.75.1.269

Gee, A., \& Troop, N. A. (2003). Shame, depressive symptoms and eating, weight and shape concerns in a non-clinical sample. Eating and Weight Disorders-Studies on Anorexia, Bulimia and Obesity, 8(1), 72-75. https://doi.org/10.1007/BF03324992 
Gilbert, P. (1998). What is shame? Some core issues and controversies. In P. Gilbert \& B.

Andrews (Eds), Shame: Interpersonal behaviour, psychopathology and culture (pp. 338). New York: Oxford University Press

Gilbert, P. (2002). Body shame. A Biopsychosocial Conceptualisation and Overview with Treatment Implications. Teoksessa Paul Gilbert \& Jeremy Miles (toim.) Body Shame. Conceptualisation, Research and Treatment. Hove: Brunner-Routledge, 3-54.

Gordon, K. H., Castro, Y., Sitnikov, L., \& Holm-Denoma, J. M. (2010). Cultural body shape ideals and eating disorder symptoms among White, Latina, and Black college women. Cultural Diversity and Ethnic Minority Psychology, 16(2), 135. https://doi.org/10.1037/a0018671

Goss, K., \& Allan, S. (2009). Shame, pride and eating disorders. Clinical Psychology \& Psychotherapy: An International Journal of Theory \& Practice, 16(4), 303-316. https://doi.org/10.1002/cpp.627

Gross, R. M., \& Nelson, E. S. (2000). Perceptions of parental messages regarding eating and weight and their impact on disordered eating. Journal of college student psychotherapy, 15(2), 57-78. https://doi.org/10.1300/J035v15n02_07

Greer, K. B., Campione-Barr, N., \& Lindell, A. K. (2015). Body talk: Siblings' use of positive and negative body self-disclosure and associations with sibling relationship quality and body-esteem. Journal of youth and adolescence, 44(8), 1567-1579. https://doi.org/10.1007/s10964-014-0180-1

Halliwell, E., \& Dittmar, H. (2004). Does size matter? The impact of model's body size on women's body-focused anxiety and advertising effectiveness. Journal of Social and Clinical Psychology, 23(1), 104-122. https://doi.org/10.1521/jscp.23.1.104.26989 
Hanna, A. C., \& Bond, M. J. (2006). Relationships between family conflict, perceived maternal verbal messages, and daughters' disturbed eating symptomatology. Appetite, 47(2), 205211. https://doi.org/10.1016/j.appet.2006.02.013

Harris, M. B., \& Koehler, K. M. (1992). Eating and exercise behaviors and attitudes of southwestern Anglos and Hispanics: Eating and Exercise Behaviors and Attitudes of Southwestern Anglos And Hispanics. Psychology and Health, 7(3), 165-174. https://doi.org/10.1080/08870449208520018

Heinberg, L. J., Thompson, J. K., \& Stormer, S. (1995). Development and validation of the sociocultural attitudes towards appearance questionnaire. International Journal of Eating Disorders, 17(1), 81-89. https://doi.org/10.1002/1098-108X(199501)17:1<81::AID-

\section{EAT2260170111>3.0.CO;2-Y}

Hitti, S. A., Avila, M., McDonald, S. E., Romo, S., Benzel, G. K., Hernandez, R. E., ... \& Corona, R. (2019). The relation between body image perceptions, parental messages, and depressive symptoms among Latinx college students. Cultural Diversity and Ethnic Minority Psychology. https://doi.org/10.1037/cdp0000309

Isasi, C. R., Rastogi, D., \& Molina, K. (2016). Health issues in Hispanic/Latino youth. Journal of Latina/o psychology, 4(2), 67. https://doi.org/10.1037/lat0000054

Jones, D. C. (2011). Interpersonal and familial influences on the development of body image. Body image: A handbook of science, practice, and prevention, 110-118.

Katrevich, A. V., Register, J. D., \& Aruguete, M. S. (2014). The Effects of Negative Body Talk in an Ethnically Diverse Sample of College Students. North American Journal of Psychology, 16(1). 
Keery, H., Boutelle, K., Van Den Berg, P., \& Thompson, J. K. (2005). The impact of appearance-related teasing by family members. Journal of Adolescent Health, 37(2), 120127. https://doi.org/10.1016/j.jadohealth.2004.08.015

Kees, J., Berry, C., Burton, S., \& Sheehan, K. (2017). An analysis of data quality: Professional panels, student subject pools, and Amazon's Mechanical Turk. Journal of Advertising, 46(1), 141-155. https://doi.org/10.1080/00913367.2016.1269304

Knight, G. P., Gonzales, N. A., Saenz, D. S., Bonds, D. D., Germán, M., Deardorff, J., ... \& Updegraff, K. A. (2010). The Mexican American cultural values scale for adolescents and adults. The Journal of early adolescence, 30(3), 444-481. https://doi.org/10.1177/0272431609338178

MacDonald, D. E., Dimitropoulos, G., Royal, S., Polanco, A., \& Dionne, M. M. (2015). The Family Fat Talk Questionnaire: Development and psychometric properties of a measure of fat talk behaviors within the family context. Body image, 12, 44-52. https://doi.org/10.1016/j.bodyim.2014.10.001

MacKinnon, D. P., Krull, J. L., \& Lockwood, C. M. (2000). Equivalence of the mediation, confounding and suppression effect. Prevention science, 1(4), 173-181. https://doi.org/10.1023/A:1026595011371

Markham, A., Thompson, T., \& Bowling, A. (2005). Determinants of body-image shame. Personality and Individual Differences, 38(7), 1529-1541. https://doi.org/10.1016/j.paid.2004.08.018

McKinley, N. M. (2011). Feminist perspectives on body image. Body image: A handbook of science, practice, and prevention, 2, 48-55. 
Monro, F., \& Huon, G. (2005). Media-portrayed idealized images, body shame, and appearance anxiety. International Journal of Eating Disorders, 38(1), 85-90. https://doi.org/10.1002/eat.20153

Neumark-Sztainer, D., Bauer, K. W., Friend, S., Hannan, P. J., Story, M., \& Berge, J. M. (2010). Family weight talk and dieting: how much do they matter for body dissatisfaction and disordered eating behaviors in adolescent girls?. Journal of Adolescent Health, 47(3), 270-276. https://doi.org/10.1016/j.jadohealth.2010.02.001

Oliveira, S., Marta-Simões, J., \& Ferreira, C. (2019). Early Parental Eating Messages and Disordered Eating: The Role of Body Shame and Inflexible Eating. The Journal of psychology, 153(6), 615-627. https://doi.org/10.1080/00223980.2019.1583162

Oliveira, S., Pires, C., \& Ferreira, C. (2020). Does the recall of caregiver eating messages exacerbate the pathogenic impact of shame on eating and weight-related difficulties?. Eating and Weight Disorders-Studies on Anorexia, Bulimia and Obesity, 25(2), 471-480. https://doi.org/10.1007/s40519-018-0625-8

Olvera, N., Matthews-Ewald, M. R., McCarley, K., Scherer, R., \& Posada, A. (2016). Hispanic maternal influences on daughters' unhealthy weight control behaviors: The role of maternal acculturation, adiposity, and body image disturbances. Body image, 19, 208215. https://doi.org/10.1016/j.bodyim.2016.10.003

Rieves, L., \& Cash, T. F. (1996). Social developmental factors and women's body-image attitudes. Journal of Social Behavior and Personality, 11(1), 63.

Rogers, C. B., Taylor, J. J., Jafari, N., \& Webb, J. B. (2019). “No seconds for you!”: Exploring a sociocultural model of fat-talking in the presence of family involving restrictive/critical 
caregiver eating messages, relational body image, and anti-fat attitudes in college women. Body image, 30, 56-63. https://doi.org/10.1016/j.bodyim.2019.05.004

Romo, L. F., \& Mireles-Rios, R. (2016). Latina immigrant mother-daughter communication about their body self-esteem and weight dissatisfaction: An exploratory videoobservational study. Journal of Latina/o Psychology, 4(1), 18. https://doi.org/10.1037/lat0000044

Schaefer, M. K., \& Salafia, E. H. B. (2014). The connection of teasing by parents, siblings, and peers with girls' body dissatisfaction and boys' drive for muscularity: The role of social comparison as a mediator. Eating behaviors, 15(4), 599-608. https://doi.org/10.1016/j.eatbeh.2014.08.018

Schooler, D., \& Lowry, L. S. (2011). Hispanic/Latino body images. Body image: A handbook of science, practice, and prevention, 237-243.

Schwarz, J. C., Barton-Henry, M. L., \& Pruzinsky, T. (1985). Assessing child-rearing behaviors: A comparison of ratings made by mother, father, child, and sibling on the CRPBI. Child development, 462-479. DOI 10.2307/1129734

Schwartz, D. J., Phares, V., Tantleff-Dunn, S., \& Thompson, J. K. (1999). Body image, psychological functioning, and parental feedback regarding physical appearance. International Journal of Eating Disorders, 25(3), 339-343. https://doi.org/10.1002/(SICI)1098-108X(199904)25:3<339::AID-EAT13>3.0.CO;2-V Shannon, A., \& Mills, J. S. (2015). Correlates, causes, and consequences of fat talk: A review. Body image, 15, 158-172. https://doi.org/10.1016/j.bodyim.2015.09.003 
Smith, J. E., Erickson, S. J., Austin, J. L., Winn, J. L., Lash, D. N., \& Amrhein, P. C. (2016). Mother-daughter relationship quality and body image in preadolescent girls. Journal of child and family studies, 25(9), 2683-2694. https://doi.org/10.1007/s10826-016-0452-3

Smith, A. R., Zuromski, K. L., \& Dodd, D. R. (2018). Eating disorders and suicidality: what we know, what we don't know, and suggestions for future research. Current opinion in psychology, 22, 63-67. https://doi.org/10.1016/j.copsyc.2017.08.023

Smolak, L. (2011). Body image development in childhood. Body image: A handbook of science, practice, and prevention, 67-75.

Spurgas, A. K. (2005). Body image and cultural background. Sociological Inquiry, 75(3), 297316. https://doi.org/10.1111/j.1475-682X.2005.00124.x

Stein, G. L., Cupito, A. M., Mendez, J. L., Prandoni, J., Huq, N., \& Westerberg, D. (2014). Familism through a developmental lens. Journal of Latina/o Psychology, 2(4), 224. https://doi.org/10.1037/lat0000025

Tiggemann, M. (2012). Sociocultural perspectives on body image. Body image: A handbook of science, practice, and prevention, 12-19.

Toro, J., Gomez-Peresmitré, G., Sentis, J., Vallés, A., Casulà, V., Castro, J., ... \& Rodriguez, R. (2006). Eating disorders and body image in Spanish and Mexican female adolescents. Social psychiatry and psychiatric epidemiology, 41(7), 556-565. DOI 10.1007/s00127006-0067-X

Troop, N. A., Allan, S., Serpell, L., \& Treasure, J. L. (2008). Shame in women with a history of eating disorders. European Eating Disorders Review: The Professional Journal of the Eating Disorders Association, 16(6), 480-488. https://doi.org/10.1002/erv.858 
Tsiantas, G., \& King, R. M. (2001). Similarities in Body Image in Sisters: The Role of Sociocultural Internalization and Social Comparison. Eating Disorders, 9(2), 141-158. https://doi.org/10.1080/10640260127717

Twamley, E. W., \& Davis, M. C. (1999). The sociocultural model of eating disturbance in young women: The effects of personal attributes and family environment. Journal of social and clinical psychology, 18(4), 467-489. https://doi.org/10.1521/jscp.1999.18.4.467

Van Diest, A. M. K., \& Tylka, T. L. (2010). The caregiver eating messages scale: Development and psychometric investigation. Body Image, 7(4), 317-326. https://doi.org/10.1016/j.bodyim.2010.06.002

Webb, J. B., Fiery, M. F., \& Jafari, N. (2016). "You better not leave me shaming!”: Conditional indirect effect analyses of anti-fat attitudes, body shame, and fat talk as a function of selfcompassion in college women. Body image, 18, 5-13.

https://doi.org/10.1016/j.bodyim.2016.04.009

Webb, J. B., Rogers, C. B., Etzel, L., \& Padro, M. P. (2018). "Mom, quit fat talking-I'm trying to eat (mindfully) here!": Evaluating a sociocultural model of family fat talk, positive body image, and mindful eating in college women. Appetite, 126, 169-175. https://doi.org/10.1016/j.appet.2018.04.003

Wertheim, E. H., \& Paxton, S. J. (2011). Body image development in adolescent girls. Body image: A handbook of science, practice, and prevention, 76-84. 


\section{APPENDIX A: FIGURES, APPENDICES, AND TABLES}

\section{Figure 1}

Conceptual model linking of the interaction effect of sociocultural attitudes on negative eating and weight messages from fathers, mothers, and sisters, and young woman's internalized and externalized body image shame.

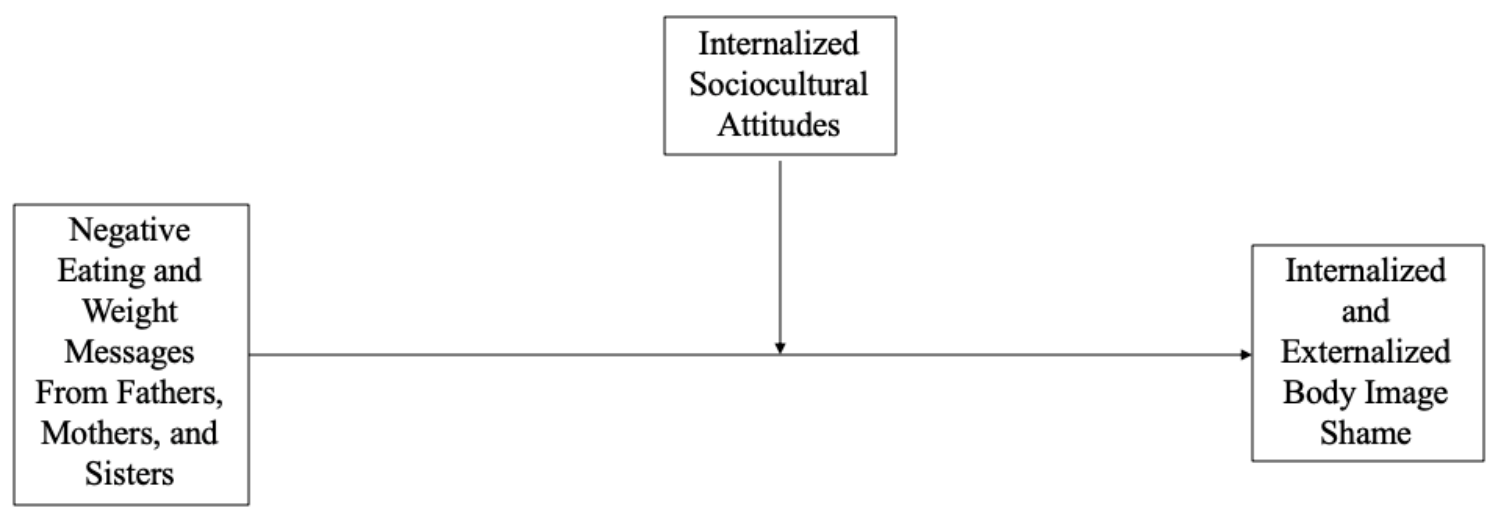




\section{Appendix A}

The Parental Eating and Weight Messages Survey

1. You need to lose weight $(R)$

2. You look like you have gained weight $(R)$

3. How much do you weigh? $(R)$

4. Do you weigh yourself? $(R)$

5. Have you gained weight? $(R)$

6. Are you going to eat THAT? $(R)$

7. Do you know how many calories are in that? $(R)$

8. That is too fattening, don't eat that $(R)$

9. If you eat that, you will get fat $(R)$

10 . You don't need to eat that $(R)$

Note. Response options are: Always (1), Frequently, (2), Sometimes (3), Rarely (4), and Never $(5)$. $(R)$ items should be reverse scored so that lower scores indicate less frequency of bodyrelated verbal messages from family members. 


\section{Appendix B}

Sociocultural Attitudes Toward Appearance

1. Women who appear in TV shows and movies project the type of appearance that I see as my goal.

2. I believe that clothes look better on thin models.

3. Music videos that show thin women make me wish I were thin.

4. I do not wish to look like the models in the magazines. $(R)$

5. I tend to compare my body to people in magazines and on TV.

6. Photographs of thin women make me wish I were thin.

7. I wish I looked like a swimsuit model.

8. I often look through social media such as Instagram and compare my appearance to the models and celebrity influencers.

Note. Response options are: Completely disagree (1), Disagree (2), Neither Agree nor

Disagree (3), Agree (4), and Completely Agree (5). (R) items should be reverse scored so that lower scores indicate lower levels of sociocultural attitudes towards appearance. 


\section{Appendix C}

Appendix C: The Body Image Shame Scale

1. I feel uncomfortable in social situations because I feel that people may criticize me because of my body shape. $E$

2. I avoid social situations (e.g., going out and parties) because of my physical appearance. $E$

3. The relationship I have with my physical appearance makes it difficult for me to feel comfortable in social situations. $E$

4. I do not like to exercise in front of other because I am afraid of how they might evaluate me. $E$

5. My physical appearance makes me feel inferior in relation to others. $E$

6. The relationship I have with my body prevents me from having an intimate relationship with someone. $E$

7. I avoid moving my body (for example, dancing) in public places because I feel I am exposing my physical appearance to the criticism of others. $E$

8. I choose clothes that hide parts of my body that I consider ugly or disproportional. I

9. There are parts of my body that I prefer to hide. I

10. I feel bad about myself when I use clothes that reveal my body shape. I

11. I avoid wearing tight clothes that reveal my body shape. $I$

12. I pay close attention to the movements and posture of my body to hide parts that I do not like. $I$

13. It bothers me to see my body undressed. $I$

14. When I see my body in the mirror I feel I am a defective person. I

15. I tend to wear darker clothes (e.g, black and/or brown) because I believe it makes me look thinner. $I$

Note. Response options are: Never (0), Seldom (1), Sometimes (2), Often (3), and Almost Always (4). The notation after each item indicates the relevant subscale (i.e., $E=$ externalized body image shame and $I=$ internalized body image shame). 


\section{Table 1}

Correlations and Descriptive Statistics for all study variables.

\begin{tabular}{|c|c|c|c|c|c|c|c|c|c|c|c|c|}
\hline & 1 & 2 & 3 & 4 & 5 & 6 & 7 & 8 & 9 & 10 & 11 & 12 \\
\hline 1. & & & & & & & & & & & & \\
\hline $\begin{array}{l}\text { Relationship } \\
\text { with Father } \\
2 \text {. }\end{array}$ & -- & & & & & & & & & & & \\
\hline $\begin{array}{l}\text { Relationship } \\
\text { with Mother } \\
3 \text {. }\end{array}$ & $.62 * *$ & -- & & & & & & & & & & \\
\hline $\begin{array}{l}\text { Relationship } \\
\text { with Sister }\end{array}$ & $.38^{* *}$ & $.52 * *$ & -- & & & & & & & & & \\
\hline $\begin{array}{l}\text { 4. Fathers' } \\
\text { Place of Birth }\end{array}$ & -.14 & -.12 & $-.16^{*}$ & -- & & & & & & & & \\
\hline $\begin{array}{l}\text { 5. Mothers' } \\
\text { Place of Birth }\end{array}$ & .02 & .00 & -.08 & $.44 * *$ & -- & & & & & & & \\
\hline 6. Birth Order & .03 & .05 & .00 & .13 & $.16^{*}$ & -- & & & & & & \\
\hline $\begin{array}{l}\text { 7. Messages } \\
\text { from Fathers }\end{array}$ & $-.20 * *$ & $-.19 * *$ & $-.14^{*}$ & $.23^{* *}$ & $.21 * *$ & $.29 * *$ & -- & & & & & \\
\hline $\begin{array}{l}\text { 8. Messages } \\
\text { from Mothers }\end{array}$ & -.10 & $-.28^{* *}$ & $-.22 * *$ & .10 & .07 & $.28 * *$ & $.71 * *$ & -- & & & & \\
\hline $\begin{array}{l}\text { 9. Messages } \\
\text { from Sisters }\end{array}$ & -.07 & $-.21 * *$ & $-.22 * *$ & .13 & $.18^{*}$ & $.31 * *$ & $.72 * *$ & $.79 * *$ & -- & & & \\
\hline 10. SATA & .00 & -.09 & -.05 & $.20 * *$ & .11 & $.23 * *$ & $.29 * *$ & $.27 * *$ & $.32 * *$ & -- & & \\
\hline 11. INT & -.10 & $-.16^{*}$ & -.06 & $.21 * *$ & .06 & $.21 * *$ & $.50 * *$ & $.43 * *$ & $.38 * *$ & $.63 * *$ & -- & \\
\hline 12. EXT & $-.20 * *$ & $-.23 * *$ & -.11 & $.23 * *$ & .07 & $.24 * *$ & $.57 * *$ & $.51 * *$ & $.42 * *$ & $.55^{* *}$ & $.90^{* *}$ & -- \\
\hline Mean & 3.76 & 4.10 & 3.38 & .70 & .74 & .28 & 2.26 & 2.33 & 2.24 & 3.24 & 1.70 & 1.55 \\
\hline$S D$ & .90 & .84 & .50 & .46 & .44 & .45 & 1.08 & 1.00 & 1.00 & .83 & 1.20 & 1.19 \\
\hline
\end{tabular}

Note. ${ }^{*} p<.05 ;{ }^{* *} p<.01$. SATA $=$ Sociocultural Attitudes Towards Appearance, INT = Internalized Body Image Shame, and EXT = Externalized Body Image Shame. 


\section{Table 2}

Means and Standard Deviations Separately for Older and Younger Sisters

\begin{tabular}{|c|c|c|c|c|c|c|}
\hline & \multicolumn{2}{|c|}{ Older Sister } & \multicolumn{2}{|c|}{ Younger Sister } & \multirow[b]{2}{*}{$t(d f)$} & \multirow[b]{2}{*}{$p$} \\
\hline & $M$ & $S D$ & $M$ & $S D$ & & \\
\hline Variable & & & & & & \\
\hline $\begin{array}{l}\text { Relationship } \\
\text { with Sister }\end{array}$ & 3.39 & .40 & 3.38 & .54 & $-.04(192)$ & $p>.05$ \\
\hline $\begin{array}{l}\text { Relationship } \\
\text { with Father }\end{array}$ & 3.80 & .77 & 3.75 & .95 & $-.39(189)$ & $p>.05$ \\
\hline $\begin{array}{l}\text { Relationship } \\
\text { with Mother }\end{array}$ & 4.16 & .74 & 4.07 & .88 & $-.68(192)$ & $p>.05$ \\
\hline $\begin{array}{l}\text { Messages } \\
\text { from Mother }\end{array}$ & 2.78 & .93 & 2.16 & .98 & $-3.99(193)$ & $p<.01$ \\
\hline $\begin{array}{l}\text { Messages } \\
\text { from Father }\end{array}$ & 2.76 & 1.01 & 2.06 & 1.05 & $-4.24(193)$ & $p<.01$ \\
\hline $\begin{array}{l}\text { Messages } \\
\text { from Sisters }\end{array}$ & 2.74 & .96 & 2.05 & .95 & $-4.49(193)$ & $p<.01$ \\
\hline SATA & 3.54 & .70 & 3.12 & .85 & $-3.20(193)$ & $p<.01$ \\
\hline INT & 2.10 & 1.11 & 1.55 & 1.20 & $-2.92(193)$ & $p<.01$ \\
\hline EXT & 2.01 & 1.11 & 1.37 & 1.18 & $-3.42(193)$ & $p<.01$ \\
\hline
\end{tabular}

Note. SATA $=$ Sociocultural Attitudes Towards Appearance, INT = Internalized Body Image Shame, and EXT = Externalized Body Image Shame. 
Table 3

Hierarchical Linear Regressions for Internalized Body Image Shame.

\begin{tabular}{|c|c|c|c|c|}
\hline Variable & $B$ & $S E \mathrm{~B}$ & $\beta$ & $F, R^{2}, \Delta F$, and $\Delta R^{2}$ \\
\hline \multicolumn{5}{|l|}{ Step 1} \\
\hline Relationship with Sister & .14 & .20 & .06 & \multirow{6}{*}{$\begin{array}{c}F(6,181)=3.39 * * \\
R^{2}=.07\end{array}$} \\
\hline Relationship with Father & .02 & .12 & .01 & \\
\hline Relationship with Mother & -.27 & .14 & -.19 & \\
\hline Fathers' place of birth & .47 & .21 & $.18 *$ & \\
\hline Mothers' place of birth & -.06 & .22 & -.02 & \\
\hline Birth order & .53 & .19 & $.20 * *$ & \\
\hline \multicolumn{5}{|l|}{ Step 2} \\
\hline Relationship with Sister & .13 & .15 & .06 & \multirow{10}{*}{$\begin{array}{c}F(10,177)= \\
19.32^{* *} \\
R^{2}=.50 \\
\Delta F=38.97^{* *} \\
\Delta R^{2}=.42\end{array}$} \\
\hline Relationship with Father & -.03 & .09 & -.03 & \\
\hline Relationship with Mother & -.05 & .11 & -.03 & \\
\hline Fathers' place of birth & .15 & .16 & .06 & \\
\hline Mothers' place of birth & -.14 & .17 & -.05 & \\
\hline Birth order & -.03 & .15 & -.01 & \\
\hline Messages from Mother & .23 & .11 & $.19 *$ & \\
\hline Messages from Father & .33 & .10 & $.30 * *$ & \\
\hline Messages from Sister & -.16 & .11 & -.13 & \\
\hline SATA & .75 & .08 & $.52 * *$ & \\
\hline \multicolumn{5}{|l|}{ Step 3} \\
\hline Relationship with Sister & .13 & .15 & .06 & \multirow{13}{*}{$\begin{array}{c}F(13,174)= \\
14.91^{* *} \\
R^{2}=.49 \\
\Delta F=.61 \\
\Delta R^{2}=.01\end{array}$} \\
\hline Relationship with Father & -.05 & .09 & -.04 & \\
\hline Relationship with Mother & -.03 & .11 & -.02 & \\
\hline Fathers' place of birth & .16 & .16 & .06 & \\
\hline Mothers' place of birth & -.14 & .17 & -.05 & \\
\hline Birth order & -.04 & .15 & -.02 & \\
\hline Messages from Mother & .25 & .11 & $.21 *$ & \\
\hline Messages from Father & .32 & .10 & $.29 * *$ & \\
\hline Messages from Sister & -.16 & .12 & -.14 & \\
\hline SATA & .74 & .09 & $.51 * *$ & \\
\hline SATA X Messages from Sister & -.17 & .14 & -.12 & \\
\hline SATA X Messages from Mother & .09 & .09 & .07 & \\
\hline SATA X Messages from Father & .07 & .12 & .05 & \\
\hline
\end{tabular}

Note. The $b$ weights are for each step in the analysis., ${ }^{* *} p<.01,{ }^{*} p<.05$. SATA $=$ Sociocultural Attitudes Towards Appearance. 


\section{Table 4}

Hierarchical Linear Regressions for Externalized Body Image Shame.

\begin{tabular}{|c|c|c|c|c|}
\hline Variable & $B$ & $S E \mathrm{~B}$ & $\beta$ & $F, R^{2}, \Delta F$, and $\Delta R^{2}$ \\
\hline \multicolumn{5}{|l|}{ Step 1} \\
\hline Relationship with Sister & .12 & .19 & .05 & \multirow{6}{*}{$\begin{array}{c}F(6,181)=5.43^{* *} \\
R^{2}=.12\end{array}$} \\
\hline Relationship with Father & -.09 & .12 & -.07 & \\
\hline Relationship with Mother & -.29 & .14 & $-.20 *$ & \\
\hline Fathers' place of birth & .51 & .21 & $.19 *$ & \\
\hline Mothers' place of birth & -.09 & .22 & -.03 & \\
\hline Birth order & .62 & .19 & $.23 * *$ & \\
\hline \multicolumn{5}{|l|}{ Step 2} \\
\hline Relationship with Sister & .11 & .15 & .05 & \multirow{10}{*}{$\begin{array}{c}F(10,177)= \\
20.73^{* *} \\
R^{2}=.51 \\
\Delta F=37.18^{* *} \\
\Delta R^{2}=.39\end{array}$} \\
\hline Relationship with Father & -.11 & .09 & -.09 & \\
\hline Relationship with Mother & -.07 & .11 & -.05 & \\
\hline Fathers' place of birth & .20 & .16 & .08 & \\
\hline Mothers' place of birth & -.17 & .17 & -.06 & \\
\hline Birth order & .06 & .15 & .02 & \\
\hline Messages from Mother & .31 & .11 & $.26 * *$ & \\
\hline Messages from Father & .41 & .10 & $.37 * *$ & \\
\hline Messages from Sister & -.22 & .11 & $-.19 *$ & \\
\hline SATA & .59 & .08 & $.41 * *$ & \\
\hline \multicolumn{5}{|l|}{ Step 3} \\
\hline Relationship with Sister & .13 & .15 & .06 & \multirow{13}{*}{$\begin{array}{c}F(13,174)= \\
16.35^{* *} \\
R^{2}=.52 \\
\Delta F=1.35 \\
\Delta R^{2}=.01\end{array}$} \\
\hline Relationship with Father & -.10 & .09 & -.07 & \\
\hline Relationship with Mother & -.09 & .11 & -.07 & \\
\hline Fathers' place of birth & .17 & .16 & .06 & \\
\hline Mothers' place of birth & -.15 & .17 & -.06 & \\
\hline Birth order & .05 & .15 & .02 & \\
\hline Messages from Mother & .31 & .11 & $.26 * *$ & \\
\hline Messages from Father & .41 & .10 & $.37 * *$ & \\
\hline Messages from Sister & -.22 & .11 & -.18 & \\
\hline SATA & .60 & .08 & $.42 * *$ & \\
\hline SATA X Messages from Sister & -.00 & .14 & -.00 & \\
\hline SATA X Messages from Mother & -.17 & .09 & -.13 & \\
\hline SATA X Messages from Father & .12 & .12 & .09 & \\
\hline
\end{tabular}
Attitudes Towards Appearance. 
Table 5

Hierarchical Linear Regressions for Internalized Body Image Shame and Externalized Body Image Shame with Step 3 removed.

Variable

Internalized Body Image Shame

Step 1

Relationship with Sister

Relationship with Father

Relationship with Mother

Fathers' place of birth

Mothers' place of birth

Birth order

Step 2

Relationship with Sister

Relationship with Father

Relationship with Mother

Fathers' place of birth

Mothers' place of birth

Birth order

Messages from Mother

Messages from Father

Messages from Sister

SATA

Externalized Body Image Shame

Step 1

Relationship with Sister

Relationship with Father

Relationship with Mother

Fathers' place of birth

Mothers' place of birth

Birth order

Step 2

Relationship with Sister

Relationship with Father

Relationship with Mother

Fathers' place of birth

Mothers' place of birth

Birth order

Messages from Mother

Messages from Father

Messages from Sister

SATA

$\begin{array}{llll}B & S E \mathrm{~B} & \beta & F, R^{2}, \Delta F \text {, and } \Delta R^{2}\end{array}$

$\begin{array}{rccc}.14 & .20 & .06 & \\ .02 & .12 & .01 & F(6,181)=3.39 * * \\ -.27 & .14 & -.19 & R^{2}=.07 \\ .47 & .21 & .18^{*} & \\ . .06 & .22 & -.02 & \\ .53 & .19 & .20^{* *} & \end{array}$

$\begin{array}{lll}.13 & .15 \quad .06\end{array}$

$\begin{array}{lll}-.03 & .09 & -.03\end{array}$

$\begin{array}{lll}-.05 & .11 & -.03\end{array}$

$.15 \quad .16 \quad .06$

$\begin{array}{lll}-.14 & .17 & -.05\end{array}$

$\begin{array}{lll}-.03 & .15 & -.01\end{array}$

$.23 \quad .11 \quad .19^{*}$

$.33 \quad .10 \quad .30^{* *}$

$-.16 \quad .11 \quad-.13$

$.75 \quad .08 \quad .52 * *$

$$
\begin{gathered}
F(10,177)=19.32 * * \\
R^{2}=.50 \\
\Delta F=38.97^{* *} \\
\Delta R^{2}=.42
\end{gathered}
$$

$\begin{array}{rccc}.12 & .19 & .05 & \\ -.09 & .12 & -.07 & F(6,181)=5.43^{* *} \\ -.29 & .14 & -.20^{*} & R^{2}=.12 \\ .51 & .21 & .19^{*} & \\ -.09 & .22 & -.03 & \\ .62 & .19 & .23^{* *} & \end{array}$

\begin{tabular}{rccc}
.11 & .15 & .05 & \\
-.11 & .09 & -.09 & \\
-.07 & .11 & -.05 & $F(10,177)=20.73^{* *}$ \\
.20 & .16 & .08 & $R^{2}=.51$ \\
-.17 & .17 & -.06 & $\Delta F=37.18^{* *}$ \\
.06 & .15 & .02 & $\Delta R^{2}=.39$ \\
.31 & .11 & $.26^{* *}$ & \\
.41 & .10 & $.37^{* *}$ & \\
-.22 & .11 & $-.19^{*}$ & \\
.59 & .08 & $.41^{* *}$ & \\
\hline
\end{tabular}

Note. The $b$ weights are for each step in the analysis., ${ }^{* *} p<.01,{ }^{*} p<.05$. SATA $=$ Sociocultural Attitudes Towards Appearance. 